Article

\title{
Nordic Cooperation in the Nuclear Safety Sector: High, Low, or Differentiated Integration?
}

\author{
Kjerstin Kjøndal \\ Department of Political Science and Management, University of Agder, 4630 Kristiansand, Norway; \\ E-Mail: kjerstin.kjondal@uia.no
}

Submitted: 27 May 2020 | Accepted: 21 August 2020 | Published: 3 November 2020

\begin{abstract}
Nordic cooperation has been depicted as eroding due to the increased importance of EU-related cooperation and integration. However, scholars propose that longstanding Nordic networks, grounded in professions and located in the state administration, may prove to be more robust toward external changes. This article discusses this proposal by looking at Nordic cooperation between the national radiation protection and nuclear safety authorities in Iceland, Denmark, Norway, Sweden, and Finland. The article maps behavioural perceptions of agency staff based on a dataset of 37 interviews to illustrate if the cooperation between the Nordic authorities is characterized by high integration, low integration, or differentiated integration within the nuclear safety sector. The study finds that the cooperation is differentiated between the highly integrated areas of radiation protection and emergency preparedness, and the less integrated areas of nuclear security and safeguards. To account for variation, the data indicates the importance of path dependency and portfolio.
\end{abstract}

\section{Keywords}

historical institutionalism; integration; Nordic cooperation; nuclear safety; nuclear security; organization theory; radiation protection; safeguards

Issue

This article is part of the issue "Rediscovering Nordic Cooperation" edited by Anne Elizabeth Stie (University of Agder, Norway) and Jarle Trondal (University of Agder, Norway/University of Oslo, Norway).

(C) 2020 by the author; licensee Cogitatio (Lisbon, Portugal). This article is licensed under a Creative Commons Attribution 4.0 International License (CC BY).

\section{Introduction}

It has been suggested that the world should look to the Nordic countries in order to build prosperous, wellgoverned, and liberal democracies. In this view, the Nordic combination of a strong state, well-functioning rule of law, and a responsible democracy is a promising recipe for good government (Lægreid, 2020, p. 421). Moreover, political scientists discuss the features of 'Nordic models' (Knutsen, 2017, p. 9), while some depict the Nordic countries as 'Nordic lights' showing the way in times of crisis (Nedergaard \& Wivel, 2018, p. 2). Scholars also ask if and how European integration through the European Union challenges and changes cooperation between the Nordic countries (Olsen \& Sverdrup, 1998, pp. 10-12). Furthermore, studies on government agencies cluster the Nordic countries together based on their geographical location and shared politico-administrative culture (Verhoest, van Thiel, Bouckaert, \& Lægreid, 2012, p. 10), and these countries are characterized by large public sectors with small core governments, numerous large agencies, and large-scale decentralization of tasks and competencies to the subnational levels of governments (Verhoest et al., 2012, p. 15). Moreover, the Nordic countries are relatively small, with informal administrative culture, a high level of mutual trust between political and administrative executives, and extremely low corruption rates (Balle Hansen, Lægreid, Pierre, \& Salminen, 2012, p. 259; Lægreid, 2018, p. 83; Verhoest et al., 2012, pp. 15-16).

The focus of this article is Nordic cooperation in the nuclear safety sector, and this sector may be divided into three different pillars: safety, safeguards, and security. Safety is defined as the protection of people, environ- 
ment, and society from the consequences of radiation. It includes radiation safety and radiation protection concerned with issues like the use of radiation in medicine. Moreover, safety covers emergency preparedness, and finally, safety encompasses nuclear safety, which in general is about how to operate nuclear facilities to avoid accidents. Safeguards is about ensuring that nuclear material, technology, and information is used for peaceful purposes, and not to develop nuclear weapons. It thus includes arms control and non-proliferation. Finally, security is linked to both safety and safeguards and it is mainly about protecting nuclear facilities from terrorism, and how to avoid theft of nuclear material, technology, and information. The article examines cooperation between the national authorities on radiation protection and nuclear safety in the five Nordic countries of Iceland, Denmark, Norway, Sweden, and Finland. A shared characteristic between these authorities is that they are expert bodies where specialized knowledge is essential, and the workforce is characterized by highly educated and skilled experts (Krick \& Holst, 2020, p. 2). An important differentiating feature is that only Sweden and Finland have nuclear power plants. Denmark and Norway have had nuclear research reactors, while Iceland never have had nuclear power-generating installations.

The article asks: Why does the degree of integration vary between issues of safety, security, and safeguards, involving the same actors, in the same sector, at the same level? To account for this variation, the article studies the effect of institutional and organizational variables. In so doing, two basic assumptions emerge: first, history and context matter (Lægreid, 2020, p. 424; Olsen, 2018). Scholars have emphasized the essential role of history and the problems of universal, non-contextual explanations by not analysing the conditions under which organizational factors are likely to have explanatory power. As different public administrations are located differently in time and space, the question is how the past affects the future and how public administrations learn-or not-from experience and changing environments (Olsen, 2018). Secondly, organization matters (Olsen, 2018). It has been argued that organization theory is a powerful instrument for approaching public governance as organizational factors are expected to create biases in governance processes, making some choices more likely than others (Egeberg \& Trondal, 2018, pp. 1-4; Lægreid, 2020, p. 422). The article therefore contributes to the organization theory-based institutional approach in public administration research (Lægreid, 2020, p. 421) by emphasising that public bureaucracies are more than instruments in the hands of national governments. They are also partly autonomous institutions that do not adapt in a simple and straightforward way to new steering signals or to changing environmental pressure (Lægreid, 2020, p. 423).

Furthermore, the phenomenon of inter-administrative coordination has been predominantly studied with a focus on their proliferation and effectiveness in pro- moting common principles, rules, and best practices (Keohane \& Nye, 1974; Slaughter, 2004). Studying the cooperation between the Nordic authorities in the nuclear safety sector adds to this literature by unpacking the cooperation itself. The study also reflects discussions on differentiated integration (Gänzle, Leruth, \& Trondal, 2020) and shows that Nordic cooperation in the nuclear safety sector best can be described as differentiated between the highly integrated safety areas of radiation protection and emergency preparedness, and the less integrated areas of nuclear safety, security, and safeguards. Finally, the article demonstrates how national authorities collaborate in a sector where parts of the portfolio are 'core state powers.' Core state powers are defined by their "institutional significance for state-building," which include foreign and defence policy, public finances, public administration, and the maintenance of law and order (Genschel \& Jachtenfuchs, 2014, p. 1). The implication is twofold: First, the case facilitates an opportunity to study the effect of non-core and core state portfolios on cooperation within the same sector; secondly, portfolios of core state powers are a hard case where highly integrated cooperation is less likely. The national authorities in the Nordic countries have portfolios reaching from non-core issues-like radiation protection-to core state issues, such as nuclear security. The study finds that the differentiated cooperation between the Nordic authorities in the nuclear safety sector mirrors the division between non-core portfolios and core-state portfolios. Hence, the data indicates the importance of path dependency as well as portfolio where integrated cooperation is more challenging to establish and maintain in core-state portfolios.

The article proceeds as follows. Section 2 outlines the theoretical framework in two steps: First, integration is defined and operationalized, and secondly, independent variables that might account for variation are outlined. Sections 3 and 4 briefly introduce the method and data, and present the empirical findings. Section 5 summarizes key findings and contributions to the literature.

\section{Theoretical Framework}

This article focuses on the organization theory-based institutional approach to public administration. In organization theory, integration is understood as the coordination between two or more actors and how they adapt collaboratively to solve a problem or provide a service (Jacobsen, 2017, p.198). Coordination is thus pictured as the purposeful alignment of tasks and efforts to achieve a defined goal (Lægreid \& Rykkja, 2015; Verhoest \& Bouckaert, 2005, p. 95). The term coordination also implies the use of mechanisms that more tightly and formally link together different units (Keast \& Mandell, 2014). Through coordination mechanisms-and thus the integration of units-synergies are created, enabling organizations to become more efficient and effective (Jacobsen, 2017, p. 197). National agencies, as public en- 
tities, are expected to create optimal value for citizens, and cooperation between agencies is thus a means to increase value. Consequently, cross-territorial cooperation between functionally similar agencies is mainly about how these agencies manage to pool and exploit common resources across territories (Jacobsen, 2017, p. 204). In literature on inter-organizational relations, coordination is defined as a behavioral process with focus on interactions and relations between actors. This approach also concentrates on how the interaction is organized, and the aim is to highlight explanations for coordinative behaviour both by looking at characteristics of the actors involved and the characteristics of how the coordination between organizations is organized or structured (Jacobsen, 2017, p. 200).

The degree of integration between the authorities is operationalized by looking at four coordination mechanisms focused on both behaviour and organizational dimensions (see Table 1). First, the most used operationalization of coordination appears to be the type and intensity of interaction between actors (Jacobsen, 2017, p. 210; Keast \& Mandell, 2014). This article thus concentrates on contact patterns and communication flows, where regular contact and communication indicate a high degree of integration. Secondly, the existence of reciprocal trust will most likely have a substantial impact on coordination, where trust makes communication flow easier, reduces costs associated with monitoring other actors in the cooperation, and dampens conflict between participants (Jacobsen, 2017, p. 211). Thirdly, high levels of integration are recognized by the degree of formalization in the cooperation. The existence of permanent structures where the actors involved can meet to coordinate activities through direct communication indicates high degrees of integration (Jacobsen, 2017, p. 207; Keast \& Mandell, 2014). Finally, the pooling of resources imply that tasks and different types of resources are 'moved out' of the original organizations, suggesting higher degrees of integration (Jacobsen, 2017, p. 208). In addition, this article includes the perceived importance of the cooperation as an indicator of the level of integration.

The degree of integration in the cooperation between the Nordic authorities on radiation protection and nuclear safety is analyzed on a continuum reaching from a low degree of integration to a high degree of integration (see Table 1).
To account for variation on the degree of integration, the article studies the effect of historical institutionalism and organization structure. While the degree of integration is not simply conditioned by these factors, the aim is to show that historical institutionalism and organizational structure adds to the understanding of which factors influence integration in cooperation between national agencies at a higher level, such as the Nordic one. The article discusses the effect of path-dependency, size, horizontal specialization, and vertical specialization on integration, by both studying properties of the Nordic cooperation itself, and also by looking at characteristics of each individual authority in the Nordic countries.

Historical institutionalism is based on the basic assumptions that history matters, and that history is not a chain of independent incidents (Steinmo, 2008). The focus is thus on the construction, maintenance, and adaptation of institutions (Sanders, 2006, p. 42), emphasizing the origin and evolution of the rules, norms, and practices shaping policy outcomes and the structure of polities (Fioretos, Falleti, \& Sheingate, 2016). The conceptual toolbox related to historical institutionalism consists of concepts like path dependence and critical junctures (Fioretos et al., 2016).

In this study, path dependency is understood as "dynamic processes involving positive feedback" (Fioretos et al., 2016) overlapping with the idea of 'increasing returns' (Pierson, 2000). These ideas capture a basic element in understanding path-dependency displaying how the costs of changing from one alternative to another will increase over time creating a self-reinforcement dynamic, making deviation from an existing path increasingly more difficult (Fioretos et al., 2016; Pierson, 2000). Path-dependent processes are born through critical junctures, understood as "a period of significant change, which typically occurs in distinct ways in different countries (or in other units of analysis) and which is hypothesized to produce distinct legacies" (Collier \& Collier, 2002, p. 29). Thus, path dependency shows how particular historical junctures have lasting consequences. However, path dependent arguments based on positive feedback propose that not only 'big' events have big consequences. Small ones, that happen at the right time, can have vast consequences as well (Pierson, 2000). Furthermore, literature on institutional change suggests that pathdependent lock-in is a rare phenomenon, opening the possibility that institutions normally evolve in incremen-

Table 1. Operationalization of integration.

\begin{tabular}{lll}
\hline Proxy & Low degree of integration & High degree of integration \\
\hline Contact pattern & Infrequent communications flows & Regular communications flows \\
Trust & Low reciprocal trust & High reciprocal trust \\
Formalization & None or ad hoc & Permanent structures \\
Resources & Resources remain in each authority & Pooled resources \\
Perceived importance $*$ & Low & High \\
\hline
\end{tabular}

Note: * Of the cooperation. Source: Based on Jacobsen (2017) and Keast and Mandell (2014). 
tal ways (Thelen \& Mahoney, 2010, p. 3). In relation to Nordic cooperation in general, Olsen and Sverdrup (1998, p. 26) suggested that longstanding Nordic networks, grounded in professions and located in the state administration, may prove to be more robust toward external changes than Nordic cooperation which lack these characteristics. In broad terms, robustness refers to a complex system's ability to remain functional and stable despite uncertainty, and also to the system's capacity to withstand and survive external shocks (Bankes, 2010; Capano \& Woo, 2017). Moreover, in organization theory, robustness refers to an organization's capacity to retain its core characteristics under evolving circumstances (van Oss \& van 't Hek, 2011, p. 4). Though discussed, robustness is often associated with the concept of resilience (Capano \& Woo, 2017; Walker, Holling, Carpenter, \& Kinzig, 2004), and both concepts may function as frameworks for understanding how complex systems self-organize and change over time (Anderies, Folke, Walker, \& Ostrom, 2013). Regarding path dependency, proposition one (\#1) is that Nordic cooperation will be more integrated if the cooperation has been successful in achieving its goals leading to positive feedbacks and selfreinforcing dynamics. Moreover, integrated cooperation is more likely if there is a longstanding history where critical junctures have strengthened the cooperation. Finally, integration increases if the cooperation has showed robustness toward external changes and shocks. The expectation is therefore that Nordic cooperation in this sector will be more integrated on issues of radiation protection, rather than on nuclear safety, security, and safeguards.

An organization structure is a normative structure consisting of rules and norms specifying, more or less clearly, who is expected to do what and how (Egeberg \& Trondal, 2018, p. 5). Different dimensions of the organizational structure enable varied insights into how structure affects individual behaviour (Egeberg \& Trondal, 2018, pp. 6-7). The following outlines three structural variables: size, horizontal specialization, and vertical specialization:

- The size of an organization indicates the capacity to initiate policies, develop alternatives, implement decisions, and monitor compliance (Egeberg \& Trondal, 2018, p. 7). Large organizations, in terms of staff size, are therefore less dependent on other actors or organizations to carry out its task, and thus they are more autonomous than smaller organizations. Consequently, small organizations must, to a greater degree than their larger counterparts, build capacity through other means, like cooperation, using the potential benefits of economies of scale (Jacobsen, 2017, p. 203). Proposition two (\#2) is thus that large authorities in this sector, like those in Sweden and Finland, will be less integrated into the Nordic cooperation than the smaller authorities in Denmark, Norway, and Iceland.
- Horizontal specialization shows how different policy areas and issues are supposed to be linked together or de-coupled from each other (Egeberg \& Trondal, 2018, p. 8). Moreover, horizontal specialization influences the division of portfolios in organizations. In the case of the Nordic authorities on radiation protection and nuclear safety, their overall portfolio may be viewed through two different lenses. The first lens divides the portfolio into core state and non-core portfolios. Core state powers portfolios are connected to foreign and defence policy and include issues like nuclear security and safeguards. The other lens divides the portfolios into the three pillars of safety, security, and safeguards. Two propositions follow: First, the expectation is that there will be both less cooperation and integration between the Nordic authorities on core state portfolios because these policy areas will be more closely tied to the national government and parent ministries (\#3). Secondly, the expectation is that cooperation between the authorities will follow departmental lines, where units with shared sector affiliation will collaborate (\#4). Hence, different parts of the national authorities will be involved in Nordic cooperation to different degrees and extent, and the cooperation between the Nordic authorities will therefore be characterized by differentiated integration.

- Vertical specialization refers to the division of labour between different hierarchical levels within or between organizations. Studies show that interorganizational specialization leads to agency officials paying significantly less attention to signals from executive politicians than their counterparts in the ministries, creating more leeway for expertbased decision-making (Egeberg \& Trondal, 2018, pp. 10, 86; Holst \& Gornitzka, 2015). Hence, vertical specialization favours agency autonomy vis-àvis the national government and parent ministries, creating leeway for expert-concerns rather than national, political concerns. Proposition five (\#5) is thus that organizations, which are de-coupled from the parent ministry, will be more likely to engage in Nordic cooperation than organizations structured as part of the parent ministry or other overarching organizations, like the authorities in Denmark.

\section{Data and Method}

To unpack the cooperation between the Nordic authorities in the nuclear safety sector, this study benefits from an original dataset based on a qualitative research method. Qualitative methods encompass rich and detailed data which may provide deep understanding. Moreover, interviews open a window into the perceptions of interviewees, their experiences, and underlying processes, enabling a better understanding of com- 
plex social realities (Buchana, Garbutt, \& Seymour, 2018; Smith \& Elger, 2014, p. 119). The interview data consists of 37 semi-structured expert interviews with officials from all of the national authorities on radiation protection and nuclear safety in the Nordic countries, conducted in 2018 and 2019. 22 interviews were conducted at the Norwegian Radiation and Nuclear Safety Authority (DSA), with the remaining 15 interviews from the authorities in Iceland, Denmark, Sweden, and Finland. All interviewees are highly educated and skilled professionals, and the data include interviews with officials from the management level of all the authorities. Staff working on communication and administration have not been included. The interviewees were selected based on their strategic position and widespread knowledge of the functioning of the authorities, and key contacts in the authorities also contributed to recruiting new interviewees. The interview questions targeted aspects of employment, internal and external contact patterns, relationship with the parent ministry, role perceptions, and experiences with international cooperation at different levels. All 37 interviews are important for the findings presented, although primarily presented at an aggregated level. Most interviews were conducted face-to-face, except five interviews conducted via Skype and Lifesize. The interviews were taped and transcribed. To preserve their anonymity, each interviewee was assigned an interview code. The data was collected in accordance with the requirements of the Norwegian Centre for Research Data.

\section{Empirical Findings}

It is not possible to narrow the cooperation between the Nordic authorities in the nuclear safety sector down to one singular cooperation. Instead, the cooperation follows the division between the three main pillars of safety, security, and safeguards. The data shows that there are important differences in how the national authorities interact within these different pillars, and there is a continuum ranging from safety issues, like radiation protection and emergency preparedness, where the cooperation is characterized by high integration, whereas in security and safeguards issues, cooperation is marked by low integration.

The cooperation on safety can be divided into four different parts: cooperation on radiation protection, emergency preparedness, the Nordic Nuclear Safety Research (NKS), and cooperation on nuclear safety. The cooperation on radiation protection and emergency preparedness is mainly organized around the Nordic chiefs meeting. Once every year the directors of the Nordic authorities gather, and they have several working groups that report to the chiefs meeting. The NKS, mainly funded by the Nordic authorities, is a platform for Nordic research on nuclear safety that includes emergency preparedness. Direct cooperation on nuclear safety is most evident between the Swedish Radiation Safety
Authority (SSM) and the Radiation and Nuclear Safety Authority (STUK) in Finland. However, there is not a general Nordic cooperation in this area comparable to the one on radiation protection and emergency preparedness. Moreover, the SSM and the STUK have a confidentiality agreement which allows them to discuss some security issues. This may indicate that the cooperation between the Swedish and Finish authorities within the nuclear safety sector is more integrated than the overall Nordic cooperation.

The Nordic chiefs meeting and the working groups on radiation protection and emergency preparedness is the most integrated cooperation between all the Nordic authorities. It is characterized by high levels of trust, continuous communication flows, some attempts to pool resources, joint projects, and permanent structures through the working groups and the annual chiefs meeting. It is also perceived as important by the interviewees. A prominent example is the Nordic Working Group of Emergency Preparedness (NEP):

We have a great Nordic cooperation with sister agencies in the other countries. We meet twice a year, all of us working on emergency preparedness in these countries. And we can have joint publications, joint working groups, joint exercises, seminars, and workshops, so it is very important for us to have this Nordic network. And of course, we cooperate with many others as well, but I would probably say that the most important sphere is the Nordic cooperation, because that is where the nearest nuclear facilities are located. That is one part of it, but it is also important to have joint Nordic recommendations, for example. So, we know each other well! (Interviewee 36)

Furthermore, interviewees underscore the importance of building strong relationships, with a foundation of trust and shared knowledge, to gain joint understandings of practices in the other countries. Another critical element to the cooperation is the need for colleagues, which is scarce at the national level, and interviewees explain why cooperation is important as follows:

The reason why this is important to us, is that the professional communities are small, and there are very few people working on every single issuesometimes just one person. So, it's very vulnerable, and to have colleagues, you must go outside your country. So, I guess that's what I'm passionate about: professional cooperation. (Interviewee 21)

Finally, attempts to pool resources and benefit mutually within the field of radiation protection are described in this way:

We are small countries with limited resources, so we don't need to do the same things in all the five countries. That's a very good output of the Nordic groups- 
it is better to cooperate, compared to everyone doing the same things by themselves. (Interviewee 2)

The modern awareness of ionizing radiation started in the late 1800 s with the discovery of $\mathrm{X}$-rays and radioactive uranium, giving rise to medical radiation. In the 1930s scientists achieved nuclear fission, which led to the construction of nuclear reactors and the atomic bomb. Indeed, the scope of both the dangers and possibilities of nuclear energy peaked during the Second World War, giving birth to cooperation targeted to encourage and facilitate safe and peaceful use of nuclear energy like the establishment of the International Atomic Energy Agency (IAEA) in 1957. The Nordic countries were also interested in peaceful use of nuclear energy and Norway, Sweden, and Denmark proved to be forerunners by building research reactors during the 1950s, while Finland had their first research reactor operating from 1962. However, only Sweden and Finland decided to construct nuclear reactors for energy production, first put into operation during the 1960s and the 1970s. Today, all the research reactors have been, or are in the process of being, decommissioned. Only reactors for energy production in Sweden and Finland continue to operate in the Nordic countries.

Regarding the historical roots of the Nordic cooperation within the nuclear safety sector, the events of the Second World War prompted the Nordic countries to have their own nuclear meetings from 1949. Eventually, this led to two parallel tracks of Nordic cooperation within this field. The first track originated in 1957 with an initiative of the Nordic Council of Ministers (NCM) to establish a permanent committee on questions related to nuclear energy: the Nordisk kontaktorgan for atomenergispørsmål (NKA). The Suez Crisis in 1956 underscored Europe's dependence on imported oil and the NKA was to oversee planning and activities in the field of atomic energy and encourage mutual assistance in case of nuclear accidents. The NKA was made up of officials from the ministries of energy, industry, and foreign affairs, accompanied by experts. Economic growth in the Nordics during the late 1960s increased the demand for electricity, making questions of nuclear power highly relevant. The NKA formed new groups to address such questions, and while the NKA grew, the organization increasingly became more complex and less transparent. The 1970s and 1980s brought growing concerns for the environment, pollution, and modern technology, exemplified by The Limits to Growth report from 1972. Simultaneously, the opposition against nuclear power grew in the Nordic countries sparked by incidents like the Three Mile Island accident in 1979. Moreover, the NKA was increasingly viewed as a controversial political actor functioning as 'a state in the state' promoting nuclear power, and eventually the NKA was dissolved after the Chernobyl disaster in 1986. However, the research branch of the NKA, the NKS, survived and the NKS is still an important part of Nordic cooperation in the nuclear safety sector.
The other track of cooperation gained importance in 1959 when the NCM recommended cooperation between the Nordic radiation protection authorities. The initiative encouraged regular expert meetings starting in 1961 and an agreement on early warning in case of an accident. While Iceland was not part of this agreement in the beginning, they joined in 1965. Initially, the cooperation addressed questions related to radioactive fallout, which was a major concern in the Nordic countries due to the culmination of nuclear bomb tests during the 1950s. The result was a joint Nordic statement on the matter and cooperation expanded and further evolved through the development of the Nordic Flag Books, dealing with international recommendations on radiation protection adapted to Nordic conditions. The first flag book from 1976 marked a significant contribution toward a common Nordic view on radiation protection. From the beginning, the Nordic countries had separate authorities for radiation protection and nuclear safety, and these authorities only interacted sporadically. However, the first directors meeting with representatives from both the radiation protection authorities and nuclear safety authorities was held in 1977, establishing the chiefs meeting with its working groups. In contrast to the cooperation through the NKA, the cooperation between the authorities strengthened after Chernobyl and led to the establishment of the NEP. Furthermore, the cooperation withstood the Fukushima accident in 2011, and the development of the newest flag book from 2014 shows that the cooperation between the Nordic Authorities continues to be important and influential:

The cooperation between the authorities was smooth and unconstrained by political influence, while the NKA was approaching the end. The authorities were praised for their handling of the impact of the Chernobyl accident, and the cooperation between the authorities continues to be very useful to this day. (Interviewee 5)

In the years after the Second World War, there was no established European cooperation between national authorities in the nuclear safety sector. However, in 1999, the Western European Nuclear Regulators Association (WENRA) was established, and in 2007 the Heads of the European Radiological Protection Competent Authorities (HERCA) was created. The WENRA deals with questions related to nuclear power plants and mainly nuclear safety issues, while The HERCA revolves around radiation protection. The data suggests the importance of both organizations, however in distinct ways. On areas where there is no established Nordic cooperation, like nuclear safety, cooperation in other arenas will be increasingly important for the authorities. Thus, on issues of nuclear safety, cooperation through the WENRA is highly important as the only organization of its kind in Europe: 
I think to some extent it has happened on nuclear safety, where we don't have that much cooperation in the Nordic countries as we have on radiation safety. And the reason is that on the nuclear safety area, we have WENRA for instance. So, we already work together very effectively and efficiently, and the goals of WENRA are aligned with our goals and the Nordic countries goals, so we don't need to have a specific cooperation forum within the Nordic countries. (Interviewee 1)

Regarding radiation protection, the Nordic cooperation was established and successful long before the HERCA was founded, and the data suggests that cooperation through the HERCA has not diminished cooperation through the chiefs meeting. The data also indicates that the Nordic authorities use the established Nordic cooperation to coordinate opinions and Nordic statements to gain leverage at the international level. Thus, Nordic cooperation on radiation protection also serves as a resource and coordination platform toward other organizations where the Nordic authorities are present:

One thing is to make our work more influential and more effective nationally, but at the international level, when we participate in certain international meetings, we first discuss within the Nordic countries. Then we might find that we all agree, and then we have more leverage to put forward certain opinions that we share. Usually we share most of the opinions, so it is quite easy to work within the Nordic countries. So, I think that at least these two points are very important in the Nordic cooperation: We have more leverage at the international level, and we can work more efficiently at the national level if we combine all our resources. (Interviewee 2)

The brief historical outline above suggests that the cooperation between the Nordic authorities on radiation protection succeeded in contributing to the development of radiation protection in the Nordic countries and also internationally by developing a common Nordic understanding manifested through joint statements and the flag books. The data thus suggests that the combination of longstanding roots and success in achieving its goals are important for explaining the highly integrated cooperation on radiation protection. As one interviewee put it: "The Nordic cooperation has been around for a long time, and it has been very influential. So, many international practices came from the Nordic groups originally, and there are several active groups on different areas" (Interviewee 2). Moreover, important critical junctures, like Chernobyl, strengthened the cooperation and it displayed robustness in its capacity to withstand and survive external shocks. The data indicates that Nordic cooperation on radiation protection also displays robustness toward changes in the organizational environment, where the cooperation upholds its important role despite new actors like the HERCA. Thus, the historical context of the cooperation makes it plausible to assume that self-reinforcement dynamics are in place, making deviation from the existing path and pattern of cooperation less likely.

Regarding Nordic cooperation through the NKA, history shows that cooperation on issues more directly related to nuclear power plants-like questions of nuclear energy, nuclear safety, and nuclear security-are more politically contested and thus more difficult to maintain over time at the Nordic level. The cooperation through the NKA was also driven by officials from the ministries, while the experts from the authorities played a minor role. The data thus indicates that the proximity to the political level may have made cooperation more turbulent. Furthermore, a series of small and large critical junctures and incremental evolvements of the organizationlike the growing skepticism to nuclear power, the declining transparency of the NKA, and the Three Mile Island accident-created an environment where, eventually, the NKA was not able to withstand the external shock of the Chernobyl accident. After the dissolvement of the NKA, other actors like the WENRA have gained influence in the field of nuclear safety, and the data suggests that path dependent mechanisms makes Nordic cooperation on nuclear safety comparable to the one on radiation protection, redundant. Thus, by studying Nordic cooperation in the nuclear safety sector after the Second World War, proposition one (\#1) holds. It shows the relevance of path dependency through positive feedback and critical junctures for understanding why cooperation on radiation protection and emergency preparedness is highly integrated at the Nordic level, compared to cooperation on issues of nuclear safety, security, and safeguards.

Considering the size variable, the Nordic authorities differ considerably in terms of how many employees the organizations have (see Table 2). The main proposition regarding size is that the largest organizations integrate into Nordic cooperation to a lesser degree than smaller structures. However, considering the most integrated part of the Nordic cooperation-cooperation on radiation protection and emergency preparedness - the

Table 2. Number of employees in the national authorities.

\begin{tabular}{lccccc}
\hline & Iceland & Denmark & Norway & Sweden & Finland \\
\hline Employees & 10 & $13^{*}$ & 120 & 300 & 333 \\
& & $40^{* *}$ & & & \\
\hline
\end{tabular}

Notes: * The Nuclear Department, ** The Radiation Protection Unit (SIS). 
data shows that all the authorities are equally committed, and they all perceive the cooperation to be important for their own organization:

I would say that the Nordic cooperation is extremely important! First of all, international cooperation is very important. For a small expert organization, it is really the only way in which you can secure and maintain competence for the staff. It is easy to get stuck when you are in a small country and you are the only organization dealing with something. So international cooperation is extremely important. But to me, the most important cooperation internationally is the Nordic cooperation. I consider the Nordic cooperation to be extremely important, and I think it is quite clear that the Nordic cooperation has improved radiation safety in the Nordic countries. (Interviewee 5)

A possible explanation is that both the Swedish and the Finnish interviewees describe their organizations as small and with limited resources. Thus, since small organizations need to build capacity through cooperation to be able to carry out their tasks, the proposition holds (\#2). The size of an organization also indicates degrees of autonomy and the capacity to initiate policies, develop alternatives, implement decisions, and monitor compliance (Egeberg \& Trondal, 2018, p. 7). The data suggests that the largest authority, the Finnish STUK, has a more active and pronounced agenda toward influencing other actors, also at the international level:

I would say that the Finns are the very best. Exactly what their strategy is, I wouldn't know, but I do know that if you look at the international context, you will almost always find a very skilled and talented Finn in different arenas, and it is quite typical that they are very accomplished within our field. (Interviewee 6)

Regarding the horizontal specialization of the Nordic authorities, the data indicates that there is less cooperation and integration between the Nordic authorities on the core-state portfolios of security and safeguards compared to the non-core portfolio of radiation protection. One possible explanation is that the foundation for such cooperation is lacking since these questions are more relevant in countries with nuclear power plants. However, the data suggests that the lack of cooperation is first and foremost related to the characteristics of security and safeguards issues. Security issues are marked by secrecy, and except some interaction between the SSM and the STUK, cooperation is scarce: "These security people are very strict, and sometimes they don't want to discuss, and because of these sensitive issues, they cannot really share information like in the safety area. You cannot compare their practices" (Interviewee 3). And: "Security is different. You can't talk about it because it's confidential, and that's why it's more difficult in the international forums" (Interviewee 1). The same follows for issues re- lated to safeguards, which in general are described as 'political,' where the main cooperation is channeled through the Ministries of Foreign Affairs and the IAEA. The data thus shows few signs of joint Nordic cooperation within both the areas of security and safeguards:

Safeguards are more political. There is much more political influence also at the technical level in this area. There is North Korea and Iran and India. Pakistan, Israel....So, it easily becomes kind of highlevel political discussions even at the technical level. (Interviewee 4)

Consequently, different parts of the authorities will be integrated into a Nordic cooperation to different degrees, where units and personnel working on issues related to security and safeguards will be least integrated. The data thus supports both propositions related to the horizontal specialization of the Nordic authorities where, first, there is less cooperation on core-state portfolios (\#3), and secondly, the cooperation follows departmental lines, where units with shared sector affiliation tend to cooperate (\#4). This leads to quite different patterns of cooperation and explains why there is not just one Nordic cooperation within the nuclear safety sector and between the national authorities. Rather, there are different arenas for cooperation which differ in their degree of integration. Furthermore, the data suggests that the difference in degree of integration partly is caused by the characteristics of core-state portfolios and non-core portfolios, where cooperation on core-state portfolios is more challenging to establish and maintain.

Furthermore, the five Nordic authorities differ in regard to both the vertical and the horizontal specialization, and the structure in Denmark stands out compared to the other four authorities. Horizontally, Iceland, Norway, Sweden, and Finland each have one agency working on issues of both safety, security, and safeguards. In Denmark, however, these policy areas are divided into two different units where the SIS mainly deals with issues of radiation protection, while the Nuclear Department focuses their work on issues of nuclear safety, security, safeguards, and emergency preparedness. Vertically, the SIS and the Danish Nuclear Department are not independent agencies, but the SIS is a department in the Danish Health Authority, while the Nuclear Department is part of the Danish Emergency Management Agency. Hence, the portfolio of the nuclear safety sector is divided between two units which serve as departments in two different agencies subordinated to different ministries. The other four Nordic authorities are independent agencies formally subordinated to one ministry, except the DSA which is formally subordinated to three different ministries. Considering the integrated Nordic cooperation on radiation protection and emergency preparedness, the data suggests that all the national agencies and the two departments in Denmark are equally involved. One explanation is that the interviewees experi- 
ence autonomy toward parent ministries and overarching agencies based on their specific knowledge and expertise: "Historically speaking, we are the experts and we have the necessary knowledge which the ministry basically lacks" (Interviewee 10). Also:

People have their own tasks and it's quite individual what you are working on. I have projects and activities I manage myself, and professionally speaking, I am the expert within my field, so, there is nobody else who has much to object or to say. (Interviewee 30)

Thus, the findings show that the authorities perceive contact with epistemic communities and experts as fundamental for the functioning of the organization:

It's important to have the international focus. So, if we turn it around: How would we manage if we didn't work internationally? It wouldn't have worked at all!....Remember, it is a small area of expertise. So, we who work within DSA would need to have very good justifications if we were to regulate radioactivity, radiation, and emissions in a completely different way than our international partners. (Interviewee 23)

But a great deal of the input we get on things that are important to us often originates from international arenas: international conferences and organizations. We take home what is necessary, and these inputs provide important premises for our further work. (Interviewee 24)

Hence, the data indicates both leeway for expert concerns and the importance of cooperation between expert bodies. The data therefore shows few signs of differences in the engagement within Nordic cooperation due to differences in the vertical specialization between different authorities (\#5).

\section{Conclusion and Outlook}

This study finds that the cooperation between the Nordic authorities in the nuclear safety sector is differentiated between the highly integrated areas of radiation protection and emergency preparedness, whereas the areas of nuclear security and safeguards is marked by low degrees of integration. To understand this variation, the article unpacks the cooperation itself by asking why these differences occur within the same sector and between the same actors. The findings suggest the importance of path dependency by highlighting two different path dependent mechanisms. First, positive feedback makes deviation from existing paths less likely, and secondly, critical junctures display the robustness of the cooperation when confronted with external shocks and changes. Thus, the longstanding history and success of the Nordic cooperation on radiation protection and emergency preparedness contributes to explaining why this coopera- tion upholds its importance. It also confirms Olsen and Sverdrup's (1998, p. 26) suggestion that longstanding Nordic networks, grounded in professions and located in the state administration, may be more robust toward external changes than Nordic cooperation, which lacks these characteristics. The findings also correspond to the division between non-core portfolios and core-state portfolios, where integrated cooperation on core-state portfolios are more difficult to establish and maintain than cooperation on non-core portfolios. Cooperation on corestate portfolios is a hard case and the findings in this study confirm this notion.

The study reflects organizational-institutional approaches to political science by suggesting that governance systems and practices under stress may revert to or strengthen established organizational traditions, practices, and formats, reinforcing institutional pathdependencies (Gänzle et al., 2020, p. 15). Thus, crises may produce critical junctures that generate 'windows of opportunity' for more integrated cooperation. The study shows under which conditions crisis and external shocks might lead to either more integrated cooperation or its breakdown. Furthermore, the study adds to the organization theory-based institutional approach in public administration research highlighting how national expert authorities, placed in the state administration, are partly autonomous institutions where a great deal of what is important originates from epistemic communities. Moreover, the findings offer insight into how crossterritorial cooperation between functionally similar authorities at the same level function and evolve over time, highlighting how they manage to pool and exploit common resources across territories. Finally, this study contributes to the study of differentiated integration (Gänzle et al., 2020) by showing how national authorities and agencies act as incoherent wholes where patterns of cooperation and degrees of integration vary within the same authority.

\section{Acknowledgments}

The author gratefully acknowledges insightful comments and suggestions from Jarle Trondal, Nadja Sophia Kühn, Barbara Zyzak, the three anonymous reviewers, and the participants at the PhD-Seminar at UiA on April 2nd, 2020. The author also expresses deep gratitude for the invaluable contributions from the interviewees.

\section{Conflict of Interests}

The author declares no conflict of interests.

\section{References}

Anderies, J. M., Folke, C., Walker, B., \& Ostrom, E. (2013). Aligning key concepts for global change policy: Robustness, resilience, and sustainability. Ecology and Society, 18(2). 
Balle Hansen, M., Lægreid, P., Pierre, J., \& Salminen, A. (2012). Comparing agencification in the Nordic countries. In G. Bouckaert, P. Lægreid, K. Verhoest, \& S. van Thiel (Eds.), Government agencies: Practices and lessons from 30 countries (pp. 259-264). Basingstoke: Palgrave Macmillan.

Bankes, S. (2010). Robustness, adaptivity, and resiliency analysis. Paper presented at the Association for the Advancement of Artificial Intelligence Fall Symposium, Arlington, VA, USA.

Buchana, Y., Garbutt, M., \& Seymour, L. F. (2018). Identifying micro-level generative mechanisms of ICT-enabled performance improvement in resource-constrained healthcare organisations: A critical realist perspective. The Electronic Journal of Information Systems in Developing Countries, 84(6), 1-11.

Capano, G., \& Woo, J. J. (2017). Resilience and robustness in policy design: A critical appraisal. Policy Sciences, 50(3), 399-426.

Collier, R., \& Collier, D. (2002). Framework: Critical junctures and historical legacies. In R. Collier \& D. Collier (Eds.), Shaping the political arena: Critical junctures, the labor movement, and regime dynamics in Latin America (pp. 27-39). Notre Dame, IN: University of Notre Dame Press.

Egeberg, M., \& Trondal, J. (2018). An organizational approach to public governance: Understanding and design. Oxford: Oxford University Press.

Fioretos, K., Falleti, T., \& Sheingate, A. (2016). Historical institutionalism in political science. In K. Fioretos, T. Falleti, \& A. Sheingate (Eds.), The Oxford handbook of historical institutionalism. Oxford: Oxford University Press. https://doi.org/10.1093/oxfordhb/ 9780199662814.013.1

Gänzle, S., Leruth, B., \& Trondal, J. (2020). Differentiation, differentiated integration and disintegration in a 'post-Brexit-era.' In S. Gänzle, B. Leruth, \& J. Trondal (Eds.), Differentiated integration and disintegration in a post-Brexit era (pp. 1-25). London: Routledge.

Genschel, P., \& Jachtenfuchs, M. (2014). Introduction: Beyond market regulation. Analysing the European integration of core state powers. In P. Genschel \& M. Jachtenfuchs (Eds.), Beyond the regulatory polity? The European integration of core state powers (pp. 1-23). Oxford: Oxford University Press.

Holst, C., \& Gornitzka, Å. (2015). The expert-executive nexus in the EU: An introduction. Politics and Governance, 3(1), 1-12.

Jacobsen, D. I. (2017). Governance at the local level: A research agenda on cross-boundary coordination. In J. Trondal (Ed.), The rise of common political order (pp. 197-216). Cheltenham: Edward Elgar Publishing.

Keast, R., \& Mandell, M. (2014). The collaborative push: Moving beyond rhetoric and gaining evidence. Journal of Management \& Governance, 18(1), 9-28.

Keohane, R., \& Nye, J. S. (1974). Transgovernmental relations and international organizations. World Politics:
A Quarterly Journal of International Relations, 27(1), 39-62.

Knutsen, O. (2017). Introduction: The nordic models. In O. Knutsen (Ed.), The Nordic models in political science: Challenged, but still viable? (pp. 9-18). Bergen: Fagbokforlaget.

Krick, E., \& Holst, C. (2020). The socio-political ties of expert bodies: How to reconcile the independence requirements of reliable expertise and the responsiveness requirement of democratic governance. In E. Krick \& C. Holst (Eds.), Experts and democratic legitimacy: Tracing the social ties of expert bodies in Europe (pp. 1-16). New York, NY: Routledge.

Lægreid, P. (2018). Nordic administrative traditions. In P. Nedergaard \& A. Wivel (Eds.), The Routledge handbook of Scandinavian politics (pp. 80-91). London: Routledge.

Lægreid, P. (2020). Public administration research in Norway: An organisational and institutional approach to political organisations. In G. Bouckaert \& W. Jann (Eds.), European perspectives for public administration (pp. 421-438). Leuven: Leuven University Press.

Lægreid, P., \& Rykkja, L. (2015). Organizing for "wicked problems": Analyzing coordination arrangements in two policy areas. International Journal of Public Sector Management, 28(6), 475-493.

Nedergaard, P., \& Wivel, A. (2018). Introduction: Scandinavian politics between myth and reality. In $P$. Nedergaard \& A. Wivel (Eds.), The Routledge handbook of Scandinavian politics (pp. 80-91). London: Routledge.

Olsen, J. (2018). The Bergen approach to public administration and political organization. Norsk Statsvitenskapelig Tidsskrift, 34(4), 188-206.

Olsen, J., \& Sverdrup, B. (1998). Europa i Norden [Europe in the Nordic region]. In J. Olsen \& B. Sverdrup (Eds.), Europa i Norden: Europeisering av nordisk samarbeid [Europe in the Nordic region: Europeanisation of Nordic cooperation] (pp. 10-33). Oslo: Tano Aschehoug.

Pierson, P. (2000). Increasing returns, path dependence, and the study of politics. The American Political Science Review, 94(2), 251-267.

Sanders, E. (2006). Historical institutionalism. In R. Rhodes, S. Binder, \& B. Rockman (Eds.), The Oxford handbook of political institutions (pp. 39-55). Oxford: Oxford University Press.

Slaughter, A. (2004). A new world order. Princeton, NJ: Princeton University Press.

Smith, C., \& Elger, T. (2014). Critical realism and interviewing subjects. In P. K. Edwards, J. O'Mahoney, \& S. Vincent (Eds.), Studying organizations using critical realism (pp. 109-131). Oxford: Oxford University Press.

Steinmo, S. (2008). Historical institutionalism. In D. Della Porta \& M. Keating (Eds.), Approaches and methodologies in the social sciences: A pluralist perspec- 
tive (pp. 118-138). Cambridge: Cambridge University Press.

Thelen, K. A., \& Mahoney, J. (2010). A theory of gradual institutional change. In K. A. Thelen \& J. Mahoney (Eds.), Explaining institutional change: Ambiguity, agency, and power (pp. 1-37). Cambridge: Cambridge University Press.

van Oss, L., \& van 't Hek, J. (2011). Why organizations fail? Robustness, tenacity, and change in organizations. London: Routledge.

Verhoest, K., \& Bouckaert, G. (2005). Machinery of government and policy capacity: The effects of specialization and coordination. In M. Painter \& J. Pierre (Eds.),
Challenges to state policy capacity: Global trends and comparative perspectives (pp. 92-111). Basingstoke: Palgrave Macmillan.

Verhoest, K., van Thiel, S., Bouckaert, G., \& Lægreid, P. (2012). Introduction. In G. Bouckaert, P. Lægreid, K. Verhoest, \& S. van Thiel (Eds.), Government agencies: Practices and lessons from 30 countries (pp. 3-17). Basingstoke: Palgrave Macmillan.

Walker, B., Holling, C. S., Carpenter, S. R., \& Kinzig, A. (2004). Resilience, adaptability and transformability in social-ecological systems. Ecology and Society, 9(2).

\section{About the Author}

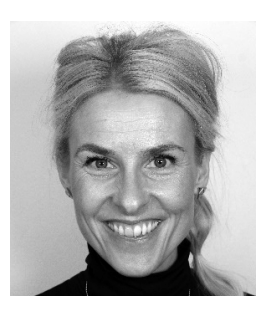

Kjerstin Kjøndal is a PhD Research Fellow at the Department of Political Science and Management at the University of Agder. Her research is primarily in the areas of public administration, international public administration, epistemic communities, and the nuclear safety sector. 